\title{
Aortic valve replacement with the Sorin Pericarbon Freedom stentless prosthesis: 7 years' experience in 130 patients
}

Augusto D’Onofrio, MD, Stefano Auriemma, MD, Paolo Magagna, MD, Alessandro Favaro, MD, Antonio Cannarella, MD, Caterina Piccin, MD, Massimo Bilotta, MD, Nicola Abbiate, MD, Nicola Lamascese, MD, and Alessandro Fabbri, MD

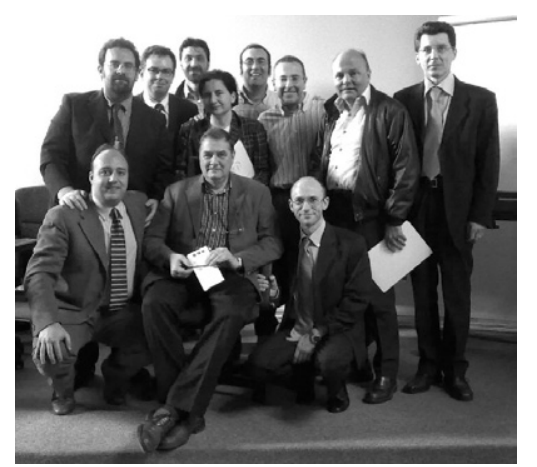

Cardiac Surgery team, San Bortolo Hospital, Vicenza, Italy
From the Division of Cardiac Surgery, San Bortolo Hospital, Vicenza, Italy.

Received for publication Feb 14, 2007; revisions received March 21, 2007; accepted for publication April 11, 2007.

Address for reprints: Augusto D’Onofrio, MD, Division of Cardiac Surgery, San Bortolo Hospital Viale Rodolfi 37, 36100 Vicenza, Italy (E-mail: adonofrio@hotmail.it; adonofrio@cardiochirurgiaitalia.it).

J Thorac Cardiovasc Surg 2007;134:491-5

$0022-5223 / \$ 32.00$

Copyright (C) 2007 by The American Association for Thoracic Surgery

doi:10.1016/j.jtcvs.2007.04.020
Objectives: Aortic stentless pericardial valves were introduced into clinical practice to combine properties of both stentless and pericardial prostheses. The aim of this single-center retrospective study was to assess midterm clinical and hemodynamic results of aortic valve replacement with the Sorin Pericarbon Freedom stentless bioprosthesis.

Methods: From July 1999 through November 2005, 130 consecutive patients (73 [56.1\%] male patients) underwent aortic valve replacement with the Sorin Pericarbon Freedom bioprosthesis at our institution. Mean age was $76 \pm 5$ years (range, 42-86 years), and associated procedures were performed in 50 (38.4\%) patients; of these, 41 were coronary artery bypass grafts. Surgical intervention under urgent/ emergency conditions and reoperations were performed in 18 (13.8\%) and $7(5.3 \%)$ patients, respectively. Mean crossclamp and cardiopulmonary bypass times were $82 \pm 24$ and $125 \pm 40$ minutes, respectively. All patients underwent clinical and echocardiographic follow-up (100\% complete), and the total cumulative follow-up was 324 patient/years (mean, $2.5 \pm 1.8$; range, 6 months -7 years).

Results: Overall hospital mortality was $8.4 \%$. Overall patient survival was $63 \% \pm$ $6 \%$ and $50 \% \pm 10 \%$ at 5 and 7 years, respectively. Late deaths occurred in 23 patients, and 6 of them were valve related (1.8\% patient/years). Freedom from valve-related death and reoperation was $91 \% \pm 4 \%$ and $94 \% \pm 4 \%$, respectively, at 7 years. No structural valve deterioration was observed. Endocarditis, thromboembolism, and hemorrhagic complications occurred in 2 (0.6\% patient/years), 1 ( $0.3 \%$ patient/years), and 1 ( $0.3 \%$ patient/years $)$ patients, respectively. Mean transprosthetic gradients for valve sizes 23,25 , and 27 were $12.1 \pm 3.8,10.8 \pm 3.8$, and $9 \pm 3.1 \mathrm{~mm} \mathrm{Hg}$, respectively.

Conclusions: The Sorin Pericarbon Freedom stentless bioprosthesis provides good early and midterm results in terms of hemodynamic performance, survival, and freedom from valve-related complications.

$\mathrm{S}$ tentless aortic bioprostheses appear to provide improved transvalvular gradients and increased orifice areas and survival rates compared with stented valves. ${ }^{1}$ Furthermore, pericardial aortic stented valves have demonstrated excellent durability, freedom from primary tissue failure, and freedom from prosthetic endocarditis. ${ }^{2,3}$

The Sorin Pericarbon Freedom (SPF; Sorin Biomedica, Saluggia, Italy) is a stentless pericardial valve prosthesis made of two sheets of pericardium sutured together without any fabric reinforcement and prepared with a postfixation treatment with homocysteic acid, which neutralizes residues of unbound aldehyde groups left after the fixation process. This peculiar design, the anticalcification treatment, and the absence of any synthetic material except for sutures should provide good results 


\section{Abbreviations and Acronyms \\ $\mathrm{AVR}=$ aortic valve replacement \\ $\mathrm{SPF}=$ Sorin Pericarbon Freedom}

in terms of hemodynamics, freedom from structural valve deterioration, and freedom from prosthetic valve endocarditis. The aim of this retrospective and single-center study was to assess early and midterm results of aortic valve replacement (AVR) with the SPF bioprosthesis.

\section{Materials and Methods \\ Study Population}

From July 1999 through December 2005, 130 consecutive patients underwent AVR with the SPF bioprosthesis at our institution. Demographic and clinical preoperative data of the study population are listed in Table 1.

Selection criteria for the implantation of the SPF bioprosthesis were as follows: age older than 65 years, contraindication to oral anticoagulant therapy, request for a biologic valve by the patient, small aortic annulus, and surgeon's preferences. Furthermore, SPF bioprostheses were intentionally implanted in patients with abscesses of the aortoventricular junction. The contraindications for the implantation of the SPF were severe calcification of the aortic annulus and aortic root aneurysm.

\section{Surgical Intervention}

Surgical intervention was performed during moderate hypothermia in all patients. Myocardial protection was obtained by using ret-

TABLE 1. Preoperative patient characteristics

\begin{tabular}{lcr}
\hline & n & $\%$ \\
\hline Age (y) & $76 \pm 5$ (range, $42-86)$ & \\
Sex & Male: 73 & 56 \\
& Female: 57 & 44 \\
History of smoking & 44 & 34 \\
Hypertension & 101 & 78 \\
Hypercholesterolemia & 61 & 47 \\
Diabetes & 30 & 23 \\
History of CVA & 12 & 9 \\
Chronic renal failure & 8 & 6 \\
Bacterial endocarditis & 8 & 6 \\
Severe COPD & 15 & 12 \\
Previous surgical intervention & 7 & 5 \\
Atrial fibrillation & 21 & 16 \\
EF (\%) & $58 \pm 14$ & \\
Urgent/emergency & 18 & 14 \\
NYHA class & I: 6 & 5 \\
& II: 23 & 18 \\
& III: 81 & 62 \\
Additive EUROscore & IV: 20 & 15 \\
\hline
\end{tabular}

CVA, Cerebrovascular accident; $C O P D$, chronic obstructive pulmonary disease; $E F$, ejection fraction; NYHA, New York Heart Association. rograde and selective antegrade cardioplegia. The SPF bioprosthesis was implanted with 3 continuous 4-0 polypropylene sutures both for the inflow and the outflow rim.

Valve sizes 21, 23, 25, and 27 were implanted in $1(0.8 \%), 57$ (43.8\%), 54 (41.6\%), and $18(13.8 \%)$ patients, respectively.

Fifty-one associated procedures were performed in $50(38.4 \%)$ patients: 41 coronary artery bypass graftings, 4 mitral valve repairs, 2 mitral valve replacements, 3 replacements of the ascending aorta, and 1 patent foramen ovale closure. Mean aortic crossclamp times were $82 \pm 24$ and $79 \pm 18$ minutes for the whole population and for isolated AVR, respectively. Mean cardiopulmonary bypass times were $125 \pm 40$ and $122 \pm 36$ minutes for the whole population and for isolated AVR, respectively. Indications for AVR were as follows: calcific aortic stenosis in 99 (76.2\%), aortic regurgitation in $10(7.7 \%)$, endocarditis in $8(6.2 \%)$, rheumatic disease in $5(3.8 \%)$, prosthesis malfunction in $6(4.6 \%)$, and congenital bicuspid valve in $2(1.5 \%)$ patients.

After implantation, oral anticoagulant therapy was prescribed in all patients and discontinued 3 months later; this is the routine anticoagulation protocol for all bioprostheses at our institution. Acetylsalicylic acid, $100 \mathrm{mg}$ daily, or ticlopidine, $250 \mathrm{mg}$ daily, were then used as antiplatelet agents. Permanent anticoagulant therapy in a dose adjusted to achieve a target international normalized ratio of 2.0 to 3.0 was prescribed in $6(5 \%)$ patients with chronic atrial arrhythmias.

\section{Follow-up}

All patients underwent scheduled visits at our outpatient clinic 1, 6 , and 12 months after the operation and on a yearly basis thereafter. Clinical follow-up was $100 \%$ complete. Mean clinical follow-up time was $2.5 \pm 1.8$ years (range, 6 months- 7 years), and total cumulative follow-up was 324 patient/years.

From January through September 2006, all of the 96 survivors (74\% of the initial study population) were purposely asked to undergo an echocardiographic evaluation. Echocardiography was performed at our institution by the same physician in $70(72.9 \%)$ patients. Twenty-six (27.1\%) patients underwent evaluation at different outside laboratories. Echocardiograms from outside laboratories were sent to us by patients or by the patients' referring cardiologists.

Mean echocardiographic follow-up time was $37.1 \pm 20$ months (range, 9.4-82.2 months). Echocardiography was performed with an iE 33 cardiac ultrasound scanner (Royal Philips Electronics, Amsterdam, The Netherlands) according to the American Society of Echocardiography guidelines. Peak and mean transvalvular pressure gradients were derived by using the modified Bernoulli equation, and the effective orifice area was calculated with the continuity equation.

Morbidity and fatal valve-related events were categorized as resulting from structural valve deterioration, nonstructural valve dysfunction, thromboembolism, prosthetic valve endocarditis, hemorrhagic complication, reoperation, valve-related mortality, or cardiac-related mortality according to the Society of Thoracic Surgeons and American Association for Thoracic Surgery guidelines for reporting morbidity and mortality after cardiac valvular operations. $^{4}$ 


\section{Statistical Analysis}

Continuous data are expressed as means \pm 1 standard deviation. Categoric data are expressed as percentages. Survival analyses with the Kaplan-Meier method were used to estimate survival and freedom from valve-related adverse events. Statistical analysis was performed with the SPSS statistical package (SPSS, Inc, Chicago, Ill). The incidence of late adverse events is shown by using linearized rates (events per 100 patient/years).

\section{Results}

Operative mortality was $8.4 \%$ (11 patients). Among these, combined coronary artery bypass grafts and mitral valve replacement were performed in 8 patients and 1 patient, respectively. Causes of early deaths were acute myocardial infarction in 4 patients, multiorgan failure in 3 patients, sepsis in 2 patients, and stroke and acute respiratory distress syndrome in 1 patient each.

Four patients had a complete atrioventricular block and needed permanent pacemaker implantation before hospital discharge.

The overall patient survival rate was $63 \% \pm 6 \%$ and $50 \% \pm 10 \%$ at 5 and 7 years, respectively (Figure 1 ). There were 23 late deaths (7.1\% patient/years). Causes and linearized rates of late deaths are listed in Table 2.

Reoperations were performed in 3 patients ( $0.9 \%$ patient/ years) during the follow-up period. Causes of reoperation were as follows: endocarditis with annular abscess and consequent valve distortion, nonstructural valve deterioration (paravalvular leak with severe regurgitation), and coronary artery disease with mild paravalvular leak. In the latter case, the valve was not replaced but once again fixed in place.

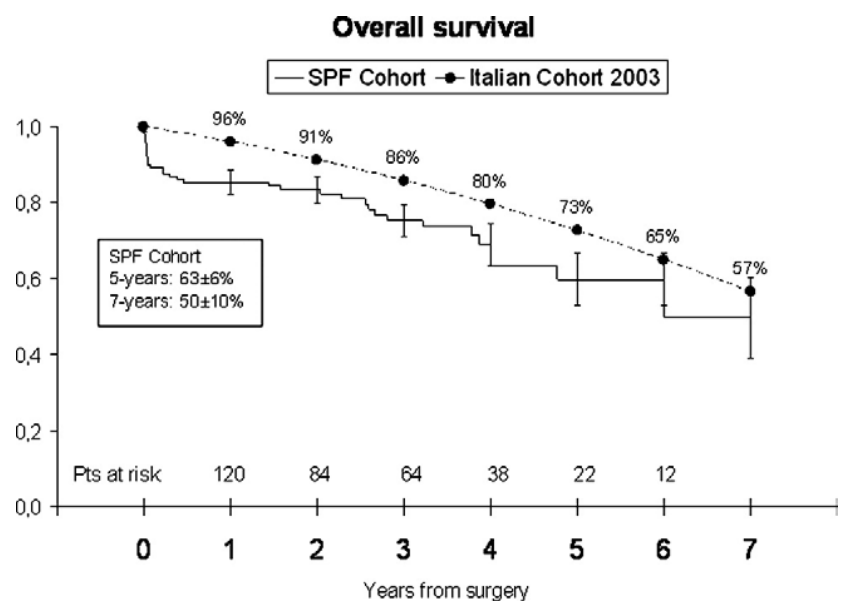

Figure 1. Kaplan-Meier survival after aortic valve replacement with the Sorin Pericarbon Freedom stentless bioprosthesis (SPF). Filled circles represent estimated survival for the 76-year-old cohort (56\% male subjects) in Italy in $\mathbf{2 0 0 3}$ (data from the Italian Institute of Statistics, www.istat.it). Vertical lines represent $\mathbf{9 5 \%}$ confidence intervals of survival for the SPF cohort.
TABLE 2. Causes and linearized rates of late deaths

\begin{tabular}{lc}
\hline Cause of late deaths & No. (\% patient/y) \\
\hline Valve related & \\
$\quad$ Sudden/unexplained/unexpected & $4(1.2)$ \\
Endocarditis & $1(0.3)$ \\
Hemorrhage & $1(0.3)$ \\
Cardiac related & \\
CHF & $5(1.5)$ \\
AMI & $2(0.6)$ \\
Noncardiac & $8(2.4)$ \\
Unknown & $2(0.6)$ \\
\hline
\end{tabular}

$C H F$, Congestive heart failure; $A M I$, acute myocardial infarction.

Freedom from valve-related death (Figure 2) and reoperation (Figure 3) was $91 \% \pm 4 \%$ and $94 \% \pm 4 \%$, respectively, at 7 years.

Endocarditis, thromboembolism, and hemorrhagic complications occurred in 2 patients $(0.6 \%$ patient/years $), 1$ patient ( $0.3 \%$ patient/years), and 1 patient $(0.3 \%$ patient/ years), respectively. One patient had the SPF bioprosthesis explanted because of a prosthetic valve endocarditis (Streptococcus bovis) 1 month after the operation. Another patient with preoperative endocarditis died of acute septic shock 2 months after the operation, and at autopsy, the aortic annulus and the bioprosthesis appeared totally destroyed. A third patient underwent a major cerebrovascular accident. This patient had a clinical preoperative history of nonsignificant carotid artery disease and of diffuse peripheral arterial atherosclerosis. Lastly, another patient, during anticoagulant therapy, had gastric bleeding requiring homologous blood transfusions.

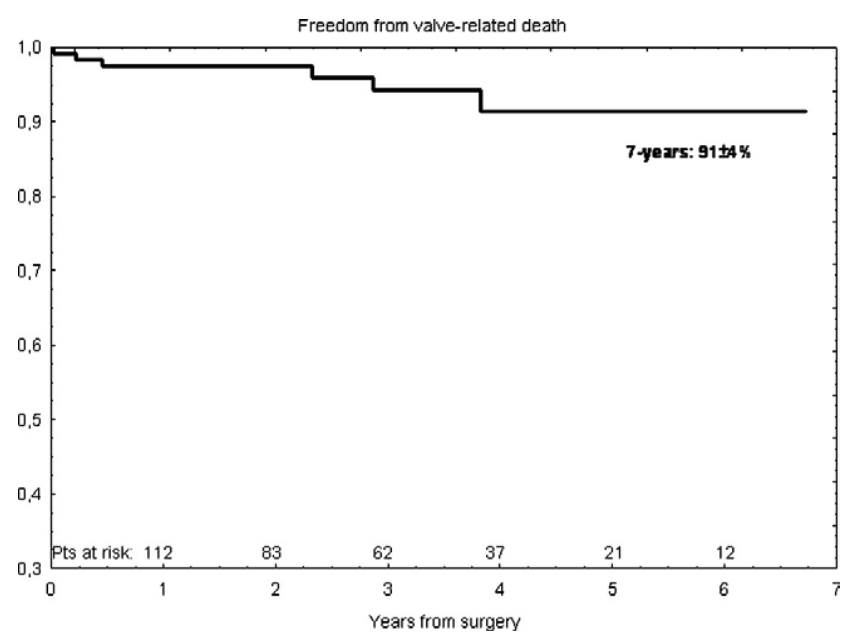

Figure 2. Kaplan-Meier freedom from valve-related death after aortic valve replacement with the Sorin Pericarbon Freedom stentless bioprosthesis. 


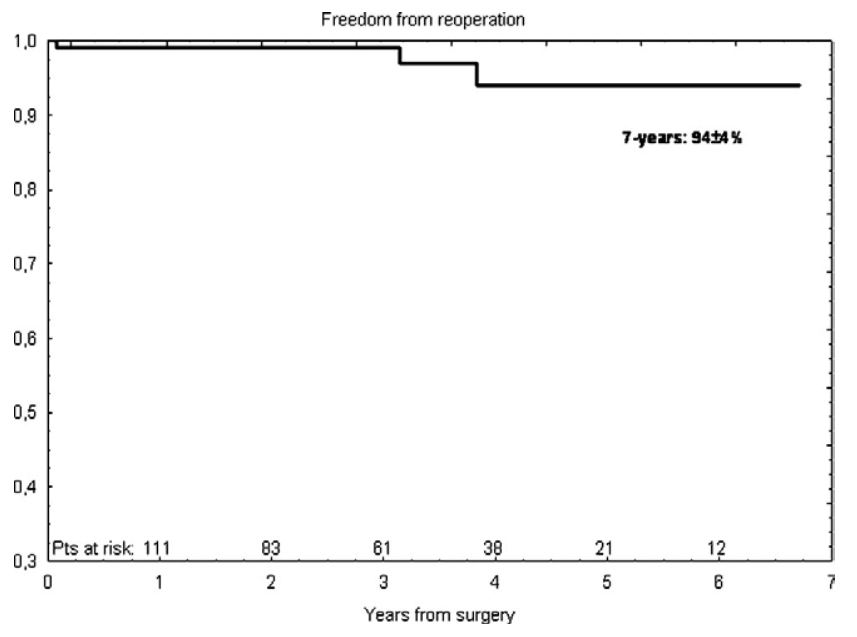

Figure 3. Kaplan-Meier freedom from reoperation after aortic valve replacement with the Sorin Pericarbon Freedom stentless bioprosthesis.

Mild aortic regurgitation was found in 4 patients $(1.2 \%$ patient/years); they are asymptomatic and scheduled to undergo an echocardiogram control every year.

Peak and mean transvalvular gradients, effective orifice area, and effective orifice area index are shown in Table 3 for valve sizes 23,25 , and 27 because only 1 patient received a size 21 prosthesis.

\section{Discussion}

Nowadays, several different models of aortic valve prostheses are available on the market. Choice depends on several issues: patient age, nature of the aortic valve disease, presence of annulus calcification, contraindication to oral anticoagulant therapy, and patient and surgeon preferences.

Tissue valves are commonly indicated in patients older than 65 years because no data support implantation in younger patients. ${ }^{5}$ Among tissue aortic valve prostheses, 2 significant distinctions need to be made: between porcine and pericardial valves and between stented and stentless valves.

The first porcine valves were implanted almost 40 years ago, ${ }^{6}$ whereas the first pericardial prostheses were introduced at the end of the 1970s. The latter initially showed a significantly higher incidence of primary failure than porcine xenografts and were temporarily abandoned. ${ }^{7}$ They were reintroduced in 1981 and approved by the US Food and Drug Administration in 1991, and since then, thousands of stented pericardial valves have been implanted in the aortic position with excellent results. Gao and colleagues ${ }^{3}$ reviewed their long-term experience with 518 stented porcine and 1021 stented pericardial valves. They found that the pericardial valve had a significantly higher rate of 10-
TABLE 3. Hemodynamic data

\begin{tabular}{lccc}
\hline & \multicolumn{3}{c}{ Valve size } \\
\cline { 2 - 4 } & $\mathbf{2 3}$ & $\mathbf{2 5}$ & $\mathbf{2 7}$ \\
\hline EOA $\left(\mathrm{cm}^{2}\right)$ & $1.7 \pm 0.6$ & $2.1 \pm 0.7$ & $2.3 \pm 0.5$ \\
EOAI $\left(\mathrm{cm}^{2} / \mathrm{m}^{2}\right)$ & $0.98 \pm 0.08$ & $1.15 \pm 0.11$ & $1.21 \pm 0.09$ \\
Peak gradient $(\mathrm{mm} \mathrm{Hg})$ & $21 \pm 7.4$ & $19.5 \pm 5.8$ & $14 \pm 2.9$ \\
Mean gradient $(\mathrm{mm} \mathrm{Hg})$ & $12.1 \pm 3.8$ & $10.8 \pm 3.8$ & $9 \pm 3.1$
\end{tabular}

$E O A$, Effective orifice area; EOAl, effective orifice area index.

year actuarial freedom from explantation when compared with the porcine prosthesis (97\% vs $90 \%, P=.04$ ).

The difference between stented and stentless valves is primarily based on hemodynamic performance. Theoretically, the absence of a stent and of a sewing ring in a stentless valve should provide more space available for blood flow and result in lower transvalvular gradients and larger effective orifice areas. Many studies have demonstrated stentless valves' superiority in terms of hemodynamics, ${ }^{1,8,9}$ survival from valve-related mortality, ${ }^{10}$ and coronary blood flow ${ }^{11}$ when compared with stented xenografts. However, recent studies have shown no significant differences in hemodynamic performance between stentless and last-generation porcine aortic valve prostheses. ${ }^{12,13}$

The SPF bioprosthesis is a stentless pericardial valve introduced into clinical practice at the end of the 1990s. Its stentless design and pericardium could play a synergic role, mixing together the advantages of both pericardial and stentless valves to extend valve durability and to improve hemodynamic performance.

We reviewed our 7-year experience with the SPF bioprosthesis, and to the best of our knowledge, this is the first medium-term report of this prosthesis.

There are 3 different implantation techniques: continuous polypropylene sutures, interrupted simple sutures, and interrupted mattress sutures. There are no hemodynamic differences among these 3 techniques. ${ }^{14}$

Our preferred implantation technique is with 3 continuous sutures for both the inflow and the outflow rim, which provides reduced crossclamp times, as previously described by Beholz and associates. ${ }^{15}$

In our experience we did not find any structural valve deterioration, and in the 3 explanted valves, the leaflets were undamaged and without any sign of calcification.

Freedom from valve-related mortality was $91 \% \pm 4 \%$ at 7 years (6 patients). Although this might appear to be rather low, one must take into consideration that 4 of 6 deaths were sudden/unexpected/unexplained, and 1 was due to a massive hemorrhage during reoperation. Furthermore, there are only few patients at risk after 5 years, and this fact inevitably causes a quick decrease of the Kaplan-Meier curve.

Nevertheless, the slope of the survival curve is similar to that of the estimated survival of the cohort from the Italian 
population matched for age and sex. The difference between the 2 curves is due only to the early mortality of the SPF cohort; this could mean that if a patient survives the operation and is successfully discharged, his life expectancy decreases over time in the same way as that of the general population.

The hemodynamics of the SPF bioprosthesis, in terms of transvalvular gradients and effective orifice areas, have been shown to be similar to those of other routinely used stentless valves. Borger and coworkers ${ }^{1}$ from Toronto, in a series of 310 stentless valves (Toronto SPV and Freestyle), reported the following midterm hemodynamic data: effective orifice area, $1.67 \pm 0.67 \mathrm{~cm}^{2}$; peak gradient, $17 \pm 10 \mathrm{~mm} \mathrm{Hg}$; and mean gradient, $9 \pm 5 \mathrm{~mm} \mathrm{Hg}$.

\section{Limitations of the study}

Limitations owing to the retrospective design of the study are present. Because of the poor life expectancy of patients in their seventh or eighth decade of life with important comorbidities, patients at risk decrease with time independently from valve-related events.

Survival and event-free curves have few patients beyond 4 years. Continued follow-up will be necessary to assess results at time points during which prosthesis failure is more likely.

Echocardiography was not performed by the same physician and with the same machine.

Preoperative and discharge echocardiographic data are not available for all patients, and thus the evaluation of hemodynamic performance development over time was not possible.

The recently published American College of Cardiology (ACC)/American Heart Association (AHA) Guidelines for the management of patients with valvular heart disease ${ }^{16}$ state that routine annual echocardiograms are not indicated in the absence of a change in the clinical status in patients with a bioprosthetic valve (class III, level of evidence C) because the expectation of structural valve deterioration in this time period is low.

\section{Conclusions}

The SPF stentless bioprosthesis appears to be a good option for AVR in elderly patients and in those with contraindications to oral anticoagulant drugs. It provided good results in terms of valve durability and freedom from valve-related complications. Echocardiographic data showed that the he- modynamic performance of the SPF bioprosthesis is excellent and overlaps that of other commercially available stentless bioprostheses.

We thank Paul Marcucci for his assistance in manuscript revision and Irene Bolgan for help in the statistical analysis of the data.

\section{References}

1. Borger MA, Carson SM, Ivanov J, et al. Stentless aortic valves are hemodynamically superior to stented valves during mid-term follow up: a large retrospective study. Ann Thorac Surg. 2005;80:2180-5.

2. Yankah CA, Shubel J, Buz S, Siniawski H, Hetzer R. Seventeen year clinical results of 1037 Mitroflow pericardial heart valve prostheses in the aortic position. J Heart Valve Dis. 2005;14:172-9.

3. Gao G, Wu Y, Grunkenmeier GL, Furnary AP, Starr A. Durability of pericardial versus porcine aortic valves. J Am Coll Cardiol. 2004;44: 384-8.

4. Edmunds LH, Clark RE, Cohn LH, Grunkenmeier GL, Miller DC, Weisel RD. Guidelines for reporting morbidity and mortality after cardiac valvular operations. Eur J Cardiothorac Surg. 1996;10:812-6.

5. Kulik A, Bédard P, Lam B-K, et al. Mechanical versus bioprosthetic valve replacement in middle-aged patients. Eur J Cardiothorac Surg. 2006;30:485-91.

6. Binet JP, Duran CMG, Carpentier A, Langlois J. Heterologous aortic valve transplantation. Lancet. 1965;2:1275-7.

7. Gallo I, Nistal F, Revuelta JM, Garcia-Satue E, Artinano E, Duran CG. Incidence of primary tissue valve failure with the Ionescu-Shiley pericardial valve. Preliminary results. J Thorac Cardiovascular Surg. 1985;90:278-80.

8. David TE, Pollick C, Bos J. Aortic valve replacement with stentless porcine aortic bioprosthesis. J Thorac Cardiovasc Surg. 1990;99: 113-8.

9. Perez de Arenaza D, Lees B, et al. Randomized comparison of stentless versus stented valves for aortic stenosis. Effect on left ventricular mass. Circulation. 2005;112:2696-702.

10. Luciani GB, Casali G, Auriemma S, Santini F, Mazzucco A. Survival after stented xenograft aortic valve replacement: a concurrent controlled trial. Ann Thorac Surg. 2002;74:1443-9.

11. Bakhtiari F, Schiemann M, Dzemali O, et al. Stentless bioprostheses improve postoperative coronary flow more than stented prostheses after valve replacement for aortic stenosis. J Thorac Cardiovasc Surg. 2006; $131: 883-8$.

12. Ali A, Halstead J, Cafferty F, et al. Are stentless valves superior to modern stented valves? Circulation. 2006;114:I535-40.

13. Chambers J, Rimington H, Hodson F, Rajani R, Blauth C. The subcoronary Toronto stentless versus supra-annular Perimount stented replacement aortic valve: early clinical and hemodynamic results of a randomized comparison in 160 patients. J Thorac Cardiovasc Surg. 2006;131:878-82.

14. Nagy ZL, Bodi A, Len A, Balogh I, Peterffy A. Three years' experience with the Sorin Pericarbon stentless prosthesis: mid-term results with three different implantation techniques. J Heart Valve Dis. 2005; 14:72-7.

15. Beholz S, Dusche S, Konertz W. Continuous suture technique for freedom stentless valve: reduced crossclamp time. Asian Cardiovasc Thorac Ann. 2006;14:128-33.

16. ACC/AHA 2006 Guidelines for the management of patients with valvular heart disease: executive summary. Circulation. 2006;114: 450-527. 